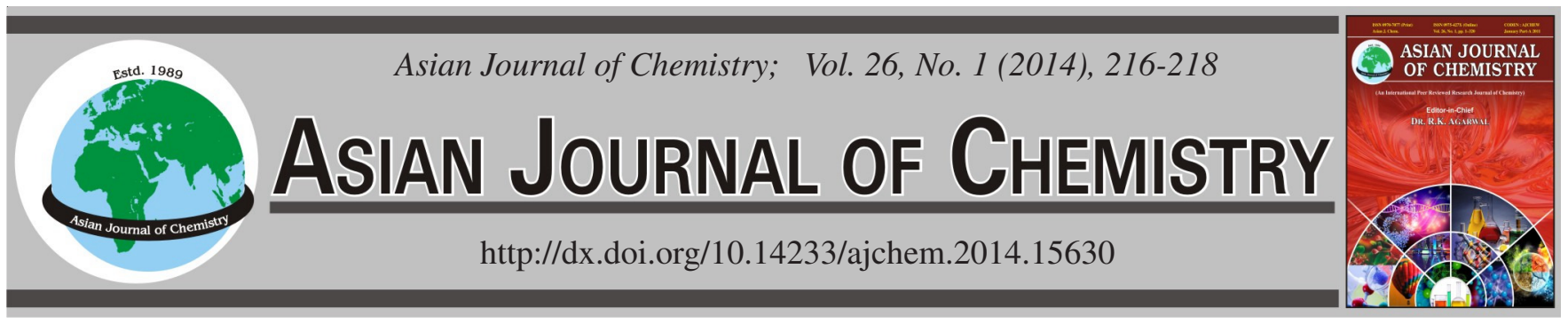

\title{
Studies on New Reagent Beryllon III and its Applications in Water Sample
}

\author{
Wen-BIN $\mathrm{CHEN}^{1, *}, \mathrm{HAI}_{\mathrm{A}} \mathrm{WNG}^{2}$ and YU-Ling Du ${ }^{2}$
}

${ }^{1}$ Jiangsu Institute of Marine Resources, Huaihai Institute of Technology, Lianyungang 222005, P.R. China

${ }^{2}$ Department of Chemical Engineering, Huaihai Institute of Technology, Lianyungang 222005, P.R. China

*Corresponding author: Tel: +86 13912168711; E-mail: lygcwb11@163.com

Received: 13 April 2013;

Accepted: 11 October 2013;

Published online: 26 December 2013;

AJC-14507

The triazene reagent beryllon III was studied along with the colour reaction with $\mathrm{Zn}$ (II) and a new spectrophotometric method for the determination of $\mathrm{Zn}$ (II). The results showed that in $\mathrm{Na}_{2} \mathrm{~B}_{4} \mathrm{O}_{7}-\mathrm{HCl}$ buffer at $\mathrm{pH} 9.10$, beryllon III reacted with $\mathrm{Zn}$ (II) and form a red stable complex. The molar ratio of reagent:metal was 2:1 and the presence of Tween-60. The maximum absorption peak of the complex was located at $532 \mathrm{~nm}$ with the apparent molar absorptivity of $1.2 \times 10^{5} \mathrm{~L} \mathrm{~mol}^{-1} \mathrm{~cm}^{-1}$. In $10 \mathrm{~mL}$ of solution, $0.06-3.5 \mu \mathrm{g}$ of Zn(II) obeyed Beer's law and the detection limit was $0.02 \mathrm{mg} / \mathrm{L}$. The colour reaction system could tolerate many interfering ions due to the existence of ammonia. This method was applied to determination of $\mathrm{Zn}(\mathrm{II})$ in water results in consistency obtained by AAS method. Recovery was also tested and values obtained were in the range of 102.5-104.1\% and the RSD $(n=6)$ of lower than $2.05 \%$.

Keywords: Beryllon III, Spectrophotometry, Zinc.

\section{INTRODUCTION}

Zinc compounds have biocidal activity because they precipitate and denature the bacterial proteins. For this reason it has been used in dermatology as an antiseptic and disinfectant agent, in ophthalmic solutions, mouthwashes and mineralvitamin preparations ${ }^{1,2}$. Zinc deposits are not only important commercially for the zinc they contain, but also because of their association with other valuable elements. About one-third of the present zinc production goes into the galvanizing of ferrous metals. Zinc is an essential element in the nutrition of animals including human beings. It acts as a cofactor in numerous of enzymes and plays an important role in protein synthesis and cell division. It exerts a crucial influence on maintenance of cell membrane stability and function of immune system. On the other hand, zinc can be toxic when exposures exceed physiological needs. After single or short term exposure to concentrations of zinc in water and beverages between 1.0 and $2.5 \mathrm{mg} / \mathrm{L}$, poisoning incidents with symptoms of gastrointestinal distress, nausea and diarrhea are reported. Concentration of zinc higher than $5 \mathrm{mg} / \mathrm{L}$ affects the potable water nature in alkaline waters. It is clear that zinc is an essential element and has significant importance, both biologically and industrially. When the quantity is more than what is required, zinc produces toxic effects. Hence, separation and determination of zinc(II) from its associated metal ions is indispensable. Many sophisticated techniques have been employed, e.g., XFS, FAAS and ICP-AES, for the determination of the total amount of metals in a diversity of complex materials. These techniques are expensive and in a number of cases beyond the normal budget. The photometric method for determination of stibium is a pop analysis method, including atomic absorption spectrometry and spectrophotometry etc, the determination of zinc(II) is a popular method of analysis. The main reagent for the measurement of zinc(II) are quinoline ${ }^{3}$, xylenol orange ${ }^{4}$, nitrophenylazo $^{5}$, triazolylazo, phenylfluorone, etc. In order to improve the selectivity of this method, toxic organic reagent benzene is used as extract reagent or mercapto cotton is used to absorb and separate during determination, but the sensitivity is usually low. Because beryllium(III) has a high intensive conjugate system, extending the scope of delocalized $\pi$ electronic system, namely exhibits outstanding optics properties. Thus the absorption spectra of the complex, forming by coordination of beryllium(III) to metal ions, were observed at 400$600 \mathrm{~nm}$, which is called spectral soret band. The photometric method with beryllium(III), which can operate easily, need short time-consuming and possess high precision and accuracy, has been applied to determine copper, molybdenum and aluminium $^{6,7}$. The colour-developing reaction condition of determination of $\mathrm{Zn}(\mathrm{II})$ with beryllon III was studied systematically in the paper. The apparent molar absorptivity measured in the experiment is $1.2 \times 10^{5} \mathrm{~L} \mathrm{~mol}^{-1} \mathrm{~cm}^{-1}$ and the presence of common ions in large quantity, including many precious metal ions, don't interfere the determination of $\mathrm{Zn}(\mathrm{II})$. EDTA is used 
as masking reagent and the presence of certain amount of highvalent metal ions is permitted. Under such condition, the method can be directly used to determine the trace $\mathrm{Zn}$ (II) of water in aqueous solution without any separation of above metal ions. Therefore it is characterized with high sensitivity, good selectivity and speediness.

\section{EXPERIMENTAL}

UNICO WFJ 7200 model spectrophotometer (Shanghai No. 5 analysis apparatus factory), pHS-3C model acidometer (Shanghai Jingke Leici Ltd.).

Stock solution of zinc(II): A foil of zinc (99.9\%, Aldrich) was washed with a $0.1 \mathrm{~mol} / \mathrm{L}$ nitric acid solution and then washed with pure acetone and air dried. $1 \mathrm{~g}( \pm 0.0002 \mathrm{~g})$ of this zinc was dissolved with concentrated nitric acid and the solution was diluted to $1000 \mathrm{~mL}$ with deionized water. Working solutions of zinc were prepared by dilution of the stock solution with water. Dilute the standard solution with distilled water to prepare $10 \mu \mathrm{g} / \mathrm{mL}$ operating solution and then dilute the standard solution to prepare $1 \mu \mathrm{g} / \mathrm{mL}$ operating solution.

Preparation of $4 \times 10^{-4} \mathrm{~mol} \mathrm{~L}^{-1}$ beryllium(III): Place $0.02 \mathrm{~g}$ of beryllium(III) in a $50 \mathrm{~mL}$ beaker and add water to dissolve it. Then the solution is transferred to a $100 \mathrm{~mL}$ volumetric flask and adds distilled water to the scale, then shake up to obtain the standard solution. Prepare $5 \mathrm{~g} \mathrm{~L}^{-1}$ of Tween80 solution by regular method. Preparation of $\mathrm{pH} 9.10$ of $\mathrm{Na}_{2} \mathrm{~B}_{4} \mathrm{O}_{7}-\mathrm{HCl}$ buffer solution: mix the prepared $0.2 \mathrm{~mol} \mathrm{~L}^{-1}$ of borax solution and $0.1 \mathrm{~mol} \mathrm{~L}^{-1}$ hydrochloric acid in the ratio of 9 to 1 and shake up, then revise its $\mathrm{pH}$ with acidometer.

The reagents used above are of analytical grade and double distilled water is used in the experiment.

Experimental method: $1.2 \mathrm{~mL}$ of $\mathrm{pH} 9.10 \mathrm{Na}_{2} \mathrm{~B}_{4} \mathrm{O}_{7}-\mathrm{HCl}$ buffer solution, $1.5 \mathrm{~mL} 5 \mathrm{~g} \mathrm{~L}^{-1}$ Tween-60 and $1.0 \mathrm{~mL}$ beryllium(III) solution are in turn added into $10 \mathrm{~mL}$ volumetric flask containing $2.0 \mathrm{~mL}$ of $1.0 \mu \mathrm{g} \mathrm{mL}^{-1} \mathrm{Zn}$ (II) working solution and added water to fixed scale then shake up. After $10 \mathrm{~min}$, the absorbency of the solution is measured at $532 \mathrm{~nm}$ in $1 \mathrm{~cm}$ cuvette and the reagent blank is used as reference.

\section{RESULTS AND DISCUSSION}

Absorption curve: The absorption spectrograms of reagent and complex are plotted according to experimental method with water and reagent blank used as reference respectively. As shown in the presence of Tween-60, the complex has high sensitivity and its maximum absorption wavelength centers on $532 \mathrm{~nm}$. While that for reagent blank on $475 \mathrm{~nm}$, the contrast is $57 \mathrm{~nm}$, so the wavelength of 532 $\mathrm{nm}$ is chosen as measure length in the paper.

Effect of systematic acidity: The effect of medium on the systematic acidity was investigated with experimental method. The results show that the optimum medium is $\mathrm{Na}_{2} \mathrm{~B}_{4} \mathrm{O}_{7}-\mathrm{HCl}$ solution, in which the maximizing absorbency and stability of the system can be reached when $\mathrm{pH}$ is in the range of 8.90-9.35. The $\mathrm{pH} 9.10$ of $\mathrm{Na}_{2} \mathrm{~B}_{4} \mathrm{O}_{7}-\mathrm{HCl}$ buffer solution is chosen to control the systematic acidity through changing its dosage between 0.8 and $1.5 \mathrm{~mL}$.Therefore 1.2 $\mathrm{mL} \mathrm{Na} \mathrm{B}_{4} \mathrm{O}_{7}-\mathrm{HCl}$ is selected to adjust systematic acidity in the following experiments.
Effect of selection and dosage of surfactant: The effect of different kinds of surfactants on the system was studied. The Tween-80 system exhibits maximizing stability and sensitivity and it not only participates in the reaction, but also enhances the solubility and sensitivity of the system. The maximizing absorbency and stability of the system can be reached when its dosage is in the range of 1.0-1.8 mL. Therefore $1.5 \mathrm{~mL}$ Tween- 60 is selected in experiment.

Effect of dosage of colour-developing agent: The maximizing absorbency and stability of the system can be reached when the dosage is in the range of $0.7-1.2 \mathrm{~mL}$, so $1 \mathrm{~mL}$ is selected in experiment.

Effect of the order of reagent addition, colour-developing time and complex stability: The absorbency of test solution is determined by changing the order of reagent addition that the order of reagent addition has great influence on the absorbency and the optimum order is the one used in the experiment. The dependence of system absorbance on time is investigated according to designed methods and the system can entirely colour-develop at room temperature, after developing $10 \mathrm{~min}$, the optimum absorbency can be obtained and keep stable for $6 \mathrm{~h}$.

Composition of complex: The composition of the complex is that the ratio of $\mathrm{Zn}$ (II):beryllon III is $1: 2$, determined by equilibrium shifting method and that of $\mathrm{Zn}(\mathrm{II})$ :beryllon III: Tween-80 is $1: 2: 2$, determined by mole ratio method and continuous variatio method. The apparent instability constant $\mathrm{K}_{\mathrm{i}}$ is $2.8 \times 10^{-15}$, while the apparent stability constant $\mathrm{K}_{\mathrm{s}}$ is 3.5 $\times 10^{14}$.

Work curve: Certain amount of $\mathrm{Zn}$ (II) standard working solution is in turn added into a series of $10 \mathrm{~mL}$ colorimetric cylinder, then undergoes colour developing and testing. The results show that $\mathrm{Zn}$ (II) content between 0.06 and $3.5 \mu \mathrm{g} / 10$ $\mathrm{mL}$ accords with Beer's law and the equation of linear regression is $A=0.1846 \rho(\mu \mathrm{g} / 10 \mathrm{~mL})+0.009$, the linearly dependent coefficient $r=0.9999$ and the apparent molar absorptivity $\varepsilon_{532} 1.2 \times 10^{5} \mathrm{~L} \mathrm{~mol}^{-1} \mathrm{~cm}^{-1}$. Relative standard deviation is $0.1 \%$ by parallel determining samples ten times and the detection limit is $0.02 \mu \mathrm{g} / \mathrm{mL}$.

Effect of coexisting ion: $5 \mathrm{mg}$ of $\mathrm{Zn}(\mathrm{II})$ is determined with experimental method and the relative error is no more than $\pm 5 \%$, and the permissible dosage $(\mu \mathrm{g})$ of coexisting ions is as following: While the permissible dosage of tartrate, citrate and triethanolamine can be present in relative large amount. Common ions such as don't interfere with the measurement. In presence of $\mathrm{Ag}^{+}, \mathrm{Hg}^{2+}$ interferes seriously, addition of $0.2 \mathrm{~mL} 100 \mathrm{~g} / \mathrm{L}$ tartaric acid can increase the dosage of masking agent upto $600 \mu \mathrm{g}$, therefore the system exhibits good selectivity. As for other coexisting ions present in low content, appropriate amount of sodium pyrophosphate and sodium fluoride can be used as masking reagent.

Water sample analyses: Respectively take $1000 \mathrm{~mL}$ network water and river water and heat them with electric furnace to condense until $100 \mathrm{~mL}$ left as samples. Respectively take an appropriate volume of sample solutions according to copper content and put them in the $10 \mathrm{~mL}$ chromogenic cuvette. Chromogenic reaction is measured according to the experimental method and the results are shown in the Table-1. 
TABLE-1

DETERMINATION RESULTS OF Zn(II) IN THE WATER SAMPLES $\mathrm{n}=6, \mu \mathrm{g} / \mathrm{L}$

\begin{tabular}{cccccc}
\hline Sample & AAS Certified* & Average & RSD $(\%)$ & Added $(\mu \mathrm{g})$ & Recovery $(\%)$ \\
\hline Network water & 35.8 & 35.1 & 3.25 & 5.0 & 102.5 \\
River water & 86.8 & 85.7 & 2.05 & 5.0 & 104.1 \\
\hline
\end{tabular}

\section{Conclusion}

The method has been used for the determination of trace $\mathrm{Zn}$ (II) in water with satisfactory results and the result was in accordance with that of the atomic absorption spectrometry method.

\section{ACKNOWLEDGEMENTS}

This article is financially supported by the Priority Academic Program Development of Jiangsu Higher Education Institutions.

\section{REFERENCES}

1. M.G.A. Korn, A.C. Ferreira, L.S.G. Teixeira, A.C.S. Costa, J. Braz. Chem. Soc., 10, 46 (1999).

2. S. Zarba and A. Pomykalski, Ann. Univ. Mariae Curie-sklodowska Lublin-Polonia, 58, 94 (2003).

3. L.W. Zhou, Food Sci. Technol., 33, 209 (2008) (in Chinese).

4. M.-H. Wang, C.-N. Zhang and Y.-F. Zheng, Rock, Miner. Anal., 27, 302 (2008) (in Chinese).

5. W. Lixiang, Y. Zhen and L. Ningjun, Anal. Instrument., 4, 42 (2007) (in Chinese).

6. R.-B. Xu, W.-X. Ma and X.-Y. Xu, Metallurg. Anal., 28, 61 (2008) (in Chinese).

7. Z.-G. Cheng, G.-X. Xu and C.-Y. Zhan, J. Huaihai Instit. Technol., 18, 47 (2009) (in Chinese). 